\title{
COLLAGENASE (MMP-1) AND TIMP-1 IN DESTRUCTIVE CORNEAL DISEASE ASSOCIATED WITH RHEUMATOID ARTHRITIS
}

\author{
G. P. RILEY ${ }^{1}$, R. L. HARRALL ${ }^{1}$, P. G. WATSON ${ }^{2}$, T. E. CAWSTON ${ }^{1}$ and B. L. HAZLEMAN ${ }^{1}$ \\ Cambridge
}

\section{SUMMARY}

The aim of the study was to immunolocalise interstitial collagenase (MMP-1) and the tissue inhibitor of metalloproteinases (TIMP-1) in ulcerating corneas from patients with rheumatoid arthritis, to determine whether changes in expression are associated with destructive corneal disease. Collagenase was expressed by stromal cells in 8 of 8 ulcerating corneas but was not seen in normal tissue $(n=3)$. TIMP-1 was abundant throughout the normal stroma, but was much reduced or absent from diseased corneas. Collagenase staining was frequently more intense near the epithelial surface and associated with a cellular infiltrate consisting of activated antigen-presenting cells (HLA-DR+), many of which were macrophages (CD68+) and derived from the epithelium or limbus (S100+). Interstitial collagenase produced by infiltrating macrophages and/or stimulated corneal fibrocytes is probably a major mediator of collagen degradation in rheumatoid corneal ulceration. In addition, reduced levels of TIMP-1 expression are consistent with collagenase activity and tissue destruction. Epithelial-stromal cell interactions and the production of local inflammatory mediators are of major importance in the pathogenesis of corneal destruction, although the precise nature of the antigenic stimulation and/or cellular interactions remains to be elucidated.

Destructive corneal disease (corneal melting or keratolysis) is a rare but potentially serious complication of auto-immune diseases such as rheumatoid arthritis. ${ }^{1}$ Destruction of corneal tissue takes many forms - from a gradual reduction in stromal thickness of the peripheral cornea (contact lens cornea) to a rapidly progressive peripheral corneal gutter or complete dissolution of corneal tissue. ${ }^{2,3}$ Except in

From: ${ }^{1}$ Rheumatology Research Unit and ${ }^{2}$ Department of Ophthalmology, Addenbrooke's Hospital, Cambridge, UK.

Correspondence to: Graham P. Riley, Rheumatology Research Unit, Box 194, Addenbrooke's Hospital, Hills Road, Cambridge CB2 2QQ, UK. Fax: 01223217838. the rare cases of corneal melting associated with severe epithelial changes of Sjögren's syndrome, these changes occur only in the vasculitic phase of rheumatoid arthritis and are always accompanied by post-capillary vascular occlusive changes adjacent to the advancing edge of the peripheral gutter. ${ }^{4}$ Histologically the reduction in the flow of these vessels is caused by high endothelium and is associated with an outpouring of inflammatory cells from the vessels. This sometimes leads to scleral inflammation, sometimes to corneal infiltration and destruction and sometimes to both. ${ }^{5}$ If the cornea is involved, then changes can sometimes occur remote from the site of any inflammatory cell infiltrate. The process can usually be reversed by intensive systemic immunosuppression, but occasionally the tissue destruction continues in spite of this, or the process has progressed so far that corneal transplantation is necessary. ${ }^{6-9}$ These transplants are at high risk both of recurrence of the original disease and from transplantation rejection, as they are either large or implanted into a vascularised cornea. ${ }^{9}$

Corneal destruction results from the loss of extracellular matrix, the majority of which is fibrillar collagen type I, and this is associated with an excess of collagen degrading activity. ${ }^{10-12}$ The exact pathogenesis is unknown, although an immunological process is implicated, driving the process of extracellular matrix degradation. The matrix metalloproteinases (MMPs) are a family of related enzymes with different substrate specificities, which together are capable of degrading all the components of the extracellular matrix. ${ }^{13,14}$ Collagenase has long been associated with corneal destruction after injury and alkali-induced burns. ${ }^{10-12}$ Since many of these early studies, however, it has been shown that there are three collagenolytic MMP enzymes with activity against fibrillar collagen. ${ }^{13,14}$ Interstitial collagenase (MMP-1) is produced by a wide variety of connective tissue cells including fibroblasts and macrophages. 
Neutrophils $(\mathrm{PMN})$ produce a different enzyme with a similar activity known as neutrophil collagenase (MMP-8). More recently a third collagenase (MMP13) has been identified, although little is known about its role in normal and pathological tissues. ${ }^{15}$ MMPs are first secreted from the cell as an inactive pro-enzyme. Activation in vivo is thought to occur by proteolytic cleavage, mediated by an enzyme cascade probably involving plasmin and/or other MMPs such as stromelysin. ${ }^{13,16}$ Once activated, control of the enzyme activity is dependent on the local concentration of tissue inhibitors of metalloproteinases (TIMPs) and other non-specific proteinase inhibitors such as $\alpha_{2}$-macroglobulin, both of which are found in normal corneas. ${ }^{17,18}$ Three closely related TIMPs have now been described, the best known of which is TIMP-1, a $28 \mathrm{kDa}$ glycosylated protein containing six disulphide bonds which binds tightly but non-covalently to active metalloproteinases to form an inactive enzyme-inhibitor complex. ${ }^{19}$

In this investigation we used well-characterised antibodies to investigate the expression of interstitial collagenase (MMP-1) and its inhibitor (TIMP-1) in rheumatoid corneas, to determine their role in destructive corneal disease.

\section{PATIENTS AND METHODS}

\section{Patients}

Eight specimens of corneas were obtained from 5 patients with seropositive rheumatoid arthritis who presented with sterile corneal ulceration during a 2year period from January 1993 to April 1995. Seven of these specimens were graft tissues which had failed following recurrence of the host disease; the remaining specimen was host tissue obtained at the first grafting operation. Normal corneal buttons $(n=3)$ were obtained from non-ulcerated eyes as controls: two specimens from cadaver eyes taken but not used for organ donation and one from a child following traumatic injury and corneal scarring.

\section{Immunohistochemistry}

Corneal discs were placed in Hank's balanced salts solution immediately after removal and processed for immunohistochemistry less than 1 hour after surgery. Specimens were fixed in ice-cold $4 \%$ paraformaldehyde for 4 hours, equilibrated in $30 \%$ sucrose and embedded in TissueTek (Miles, USA). Antigens were detected on frozen sections of 7-10 $\mu \mathrm{m}$, using the peroxidase-antiperoxidase (PAP) technique combined with a metal-enhanced 3,3'-diaminobenzamidine (DAB) substrate (Pierce, USA). In pilot experiments, peroxidase staining was superior to immunofluorescence due to the high background fluorescence associated with many of the corneas. Endogenous peroxidase activity was suppressed by pre-incubating sections for 20 minutes with a commercially available peroxidase suppressor (Pierce, USA). Some sections were pre-treated with $1000 \mathrm{U} / \mathrm{ml}$ bovine testicular hyaluronidase (Calbiochem) for 1 hour at $37{ }^{\circ} \mathrm{C}$, to remove glycosaminoglycans and expose hidden epitopes, although this procedure was found to reduce the intensity of matrix staining for collagenase. All subsequent immunolocalisation was conducted without enzymatic pre-treatment. Near-adjacent sections were stained with haematoxylin and eosin. Microscopy was performed on a Nikon Microphot-SA fluorescence photomicroscope and representative fields were photographed using Kodak EKTAR 25 professional film and a $\times 20$ objective lens.

\section{Antibodies to MMP-1 and TIMP-1}

The polyclonal and monoclonal antibodies to collagenase and TIMP used in this study have previously been exhaustively characterised, both in our laboratory and elsewhere.$^{20-23}$ Briefly, polyclonal antibodies specific to MMP-1 and TIMP-1 were prepared in rabbits, purified by protein A affinity chromatography and mono-specificity tested by Ouchterlony analysis, rocket immunoelectrophoresis and immunoblotting. There was no crossreactivity of the anti-collagenase antibody with neutrophil collagenase (MMP-8) or other MMPs. Polyclonal antibodies were diluted in phosphatebuffered saline (PBS) containing $0.1 \%$ bovine serum albumin (BSA) to a final concentration of $20 \mu \mathrm{g} / \mathrm{ml}$ and $80 \mu \mathrm{g} / \mathrm{ml}$ for anti-TIMP-1 and anti-collagenase respectively. Pre-immune rabbit immunoglobulins were used at the same concentration for negative controls. Two hybridomas (RRU-CL1 and RRUCL2) secreting monoclonal antibodies to human interstitial collagenase were produced as described elsewhere $^{20,22}$ and used on tissue sections at a final concentration of $20 \mu \mathrm{g} / \mathrm{ml}$. Mouse immunoglobulins (Dako, UK) were used as negative controls.

\section{Antibodies to Cell-Specific Antigens}

Monoclonal antibodies specific for helper $\mathrm{T}$ cells (CD4), cytotoxic T cells (CD8), monocytes/macro phages (CD68), antigen-presenting cells (HLA-DR) and cells of neuro-ectodermal origin (S100) were obtained from Dako (UK) and used as recommended by the manufacturer. Frozen sections of inflamed human tonsil and purified mouse immuno. globulins (Dako, UK) were used for positive and negative controls respectively.

\section{RESULTS}

\section{Normal Corneas}

Non-ulcerating corneas were examined to determine the normal levels of expression of collagenase and TIMP. A representative specimen is shown in Fig. 1.

There was no detectable collagenase in the stroma 


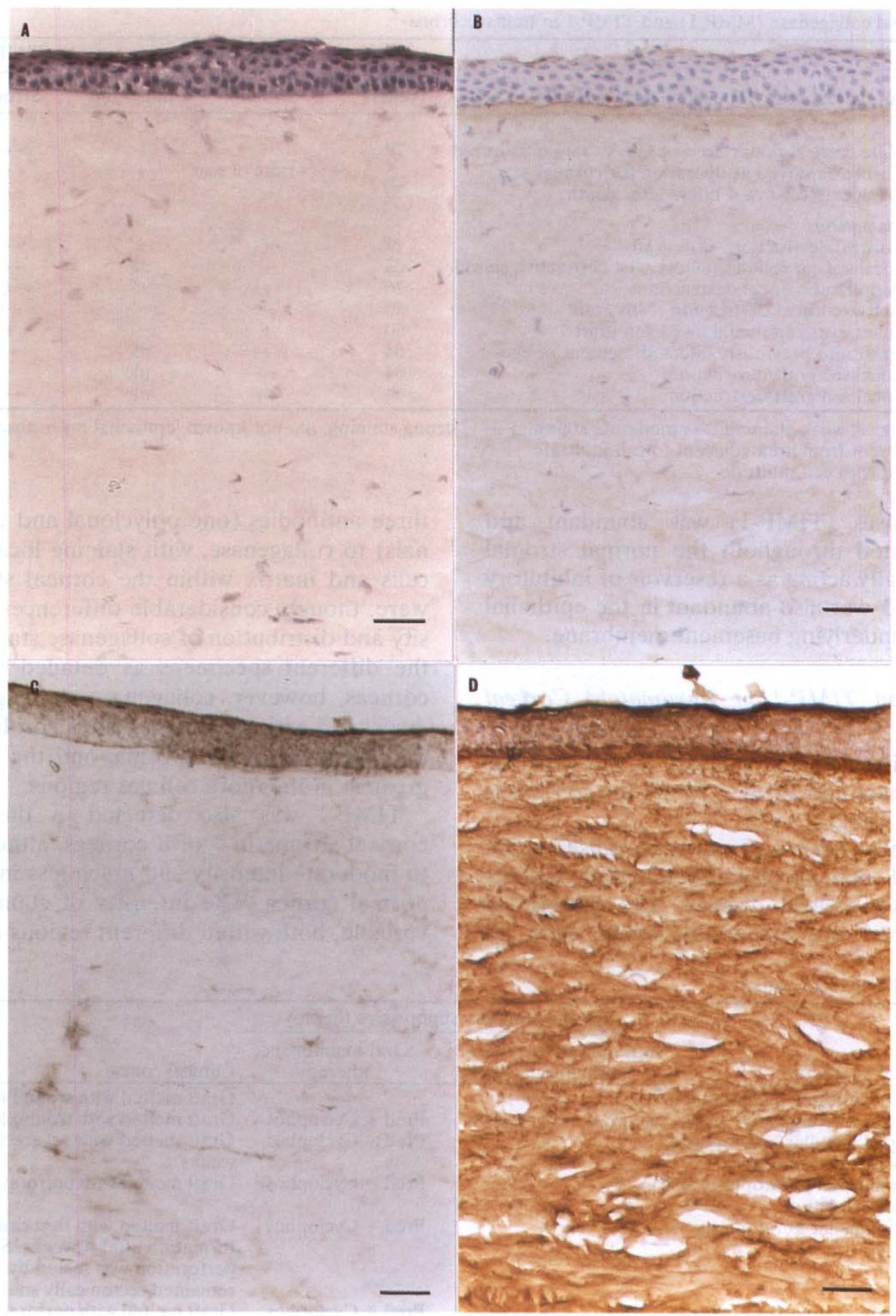

Fig. 1. Normal cornea from a 5-year-old, cryosectioned for histology and immunoperoxidase staining for collagenase and TIMP-1. (A) H\&E stain showing normal histology of corneal stroma and epithelium. (B) Negative control with pre-immune rabbit sera, counterstained with haematoxylin. (C) Monoclonal antibody RRU-CL2, showing weak collagenase (MMP-1) expression in the epithelial cell layer, but not in the corneal stroma. (D) Rabbit polyclonal antibody to TIMP-1, showing abundance of TIMP-1 throughout the corneal stroma, epithelium and basement membrane. Scale bars represent $50 \mu \mathrm{m}$.

of normal corneas, although there was weak expression in the epithelial cell layer. In one specimen we did find a focus of cells expressing collagenase, but this was associated with previous trauma and scarring in the cornea (not shown). In contrast to collagenase, the tissue inhibitor of 
Table I. Interstitial collagenase (MMP-1) and TIMP-1 in human cornea

\begin{tabular}{|c|c|c|c|c|c|c|}
\hline \multirow{2}{*}{$\begin{array}{l}\text { Patient/ } \\
\text { specimen no. }\end{array}$} & \multirow[b]{2}{*}{ Source of corneal specimen } & \multirow{2}{*}{$\begin{array}{c}\text { Age } \\
\text { (years) }\end{array}$} & \multicolumn{2}{|c|}{ MMP-1 distribution } & \multicolumn{2}{|c|}{ TIMP-1 distribution } \\
\hline & & & Stroma & Epithelium & Stroma & Epithelium \\
\hline \multicolumn{7}{|c|}{ 'Normal' controls } \\
\hline 1 & Male corneal donor died of CVA - organ cultured & 79 & - & + & +++ & ++ \\
\hline 2 & Cornea removed at operation for corneal scar & 5 & $-;(+)$ site of scar & + & +++ & ++ \\
\hline 3 & Fresh cadaver eye 4 hours after death & 70 & - & + & +++ & ++ \\
\hline \multicolumn{7}{|c|}{ Rheumatoid arthritis patients } \\
\hline 1 & Corneal destruction -8 th graft & 74 & +++ & $-{ }^{\mathrm{a}}$ & $++^{b}$ & nk \\
\hline 2 & Localised corneal destruction - 1st destructive episode & 65 & + & $\mathrm{nk}$ & $++^{\mathrm{b}}$ & nk \\
\hline 3 & Peripheral corneal destruction & 76 & +++ & $t^{\mathrm{a}}$ & $++(+)$ & ++ \\
\hline 4 no. 1 & Active corneal destruction -4 th graft & 50 & ++ & ++ & ++ & ++ \\
\hline no. 2 & Quiet eye - epithelial loss - 6th graft & 50 & + & + & + & + \\
\hline 5 no. 1 & Graft into previously infected segment of eye & 64 & +++ & $\mathrm{nk}$ & ++ & $\mathrm{nk}$ \\
\hline no. 2 & Localised graft destruction & 64 & ++ & $\mathrm{nk}$ & - & - \\
\hline no. 3 & Localised graft destruction & 64 & ++ & nk & $++^{\mathrm{b}}$ & nk \\
\hline
\end{tabular}

- , negative staining; +, weak staining; ++, moderate staining; +++, strong staining; nk, not known, epithelial layer absent.

${ }^{a}$ Epithelial layer absent from area adjacent to cell infiltrate.

btaining associated with cell infiltrate.

metalloproteinases (TIMP-1) was abundant and evenly distributed throughout the normal stromal matrix, potentially acting as a reservoir of inhibitory activity. TIMP-1 was also abundant in the epithelial layer and the underlying basement membrane.

\section{Collagenase and TIMP-1 in Rheumatoid Corneal Disease}

The immunohistochemical analysis of the distribution of collagenase and TIMP-1 for all the corneas is summarised in Table I.

Interstitial collagenase was immunolocalised to the stroma in all 8 corneas from rheumatoid patients with destructive corneal disease. The pattern of staining obtained was essentially similar with all three antibodies (one polyclonal and two monoclonals) to collagenase, with staining localised both to cells and matrix within the corneal stroma. There were, though, considerable differences in the intensity and distribution of collagenase staining between the different specimens as detailed below. In all corneas, however, collagenase staining was closely associated with regions of cellular proliferation and/ or infiltration of the stroma, and the intensity was greatest in the more cellular regions.

TIMP-1 was also detected in the rheumatoid corneal stroma in 7 of 8 corneas, although of weak to moderate intensity and much less intense than in normal cornea. The intensity of staining was also variable, both within different regions of the stroma

Table II. Clinical history of patient 1

\begin{tabular}{|c|c|c|c|c|}
\hline \multirow[b]{2}{*}{ Date } & \multirow[b]{2}{*}{ Surgical procedure } & \multicolumn{2}{|c|}{ Systemic immunosuppressive therapy } & \multirow[b]{2}{*}{ Clinical course } \\
\hline & & $\begin{array}{l}\text { Intraoperative pulse of i.v. } \\
\text { methylprednisolone }\end{array}$ & $\begin{array}{l}\text { Oral maintenance } \\
\text { therapy }\end{array}$ & \\
\hline 26 July 89 & $5 \mathrm{~mm}$ penetrating patch graft & + & & Graft melted with wound leak after 1 week \\
\hline 1 Aug. 89 & $5 \mathrm{~mm}$ penetrating patch graft & Me Pred + Cyclophos ${ }^{\mathrm{a}}$ & Pred + Cyclophos & Graft melted with wound leak after 1 week \\
\hline 8 Aug. 89 & $\begin{array}{l}\text { D-shaped lamellar keratoplasty } \\
\text { to superior half of cornea }\end{array}$ & + & Pred + Cyclophos & $\begin{array}{l}\text { Graft melted with severe thinning after } 3 \\
\text { weeks }\end{array}$ \\
\hline 2 Sept. 89 & $\begin{array}{l}12 \text { mm lamellar keratoplasty and } \\
\text { cataract extraction }\end{array}$ & + & Pred + Cyclophos & Graft melted with perforation after 6 weeks \\
\hline 2 Nov. 89 & $10 \mathrm{~mm}$ lamellar keratoplasty & + & Pred + Cyclophos & $\begin{array}{l}\text { Graft melted with descemetocoele } \\
\text { formation after } 4 \text { weeks. Subsequent } \\
\text { perforation was sealed by iris and the graft } \\
\text { remained tectonically sound for } 30 \text { months }\end{array}$ \\
\hline 2 June 92 & $6 \mathrm{~mm}$ penetrating keratoplasty & + & Pred + Cyclophos & Graft melted with perforation after 4 weeks \\
\hline 11 July 92 & $8 \mathrm{~mm}$ penetrating keratoplasty & + & Pred + CsA + Aza & $\begin{array}{l}\text { Grafted melted with perforation after } 4 \\
\text { weeks }\end{array}$ \\
\hline 3 Nov. $92 *$ & $11 \mathrm{~mm}$ penetrating keratoplasty & + & Pred + CsA + Aza & $\begin{array}{l}\text { Acute allograft rejection after } 3 \text { weeks } \\
\text { (diffuse graft oedema and keratic } \\
\text { precipitates). Resolved with topical } \\
\text { dexamethosone } 0.1 \% \text { and pulsed i.v. Me } \\
\text { Pred. ( } 500 \mathrm{mg} \text { ). Graft melted } 3 \text { weeks later } \\
\text { and perforated }\end{array}$ \\
\hline
\end{tabular}

Pred, prednisolone (15 mg/day), Cyclophos, cyclophosphamide (150 mg/day); CsA, cyclosporin A (3 mg/kg/day); Aza, Azathioprine (100 $\mathrm{mg} /$ day).

*Specimen taken for immunohistochemistry.

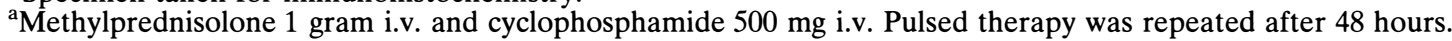

The donor material used was organ-cultured tissue for each of the first nine grafts performed and fresh tissue was used for the final corneoscleral graft.

The same surgeon (P.G.W.) performed each graft. Topical dexamethasone $0.1 \%$ was administered after each graft. 


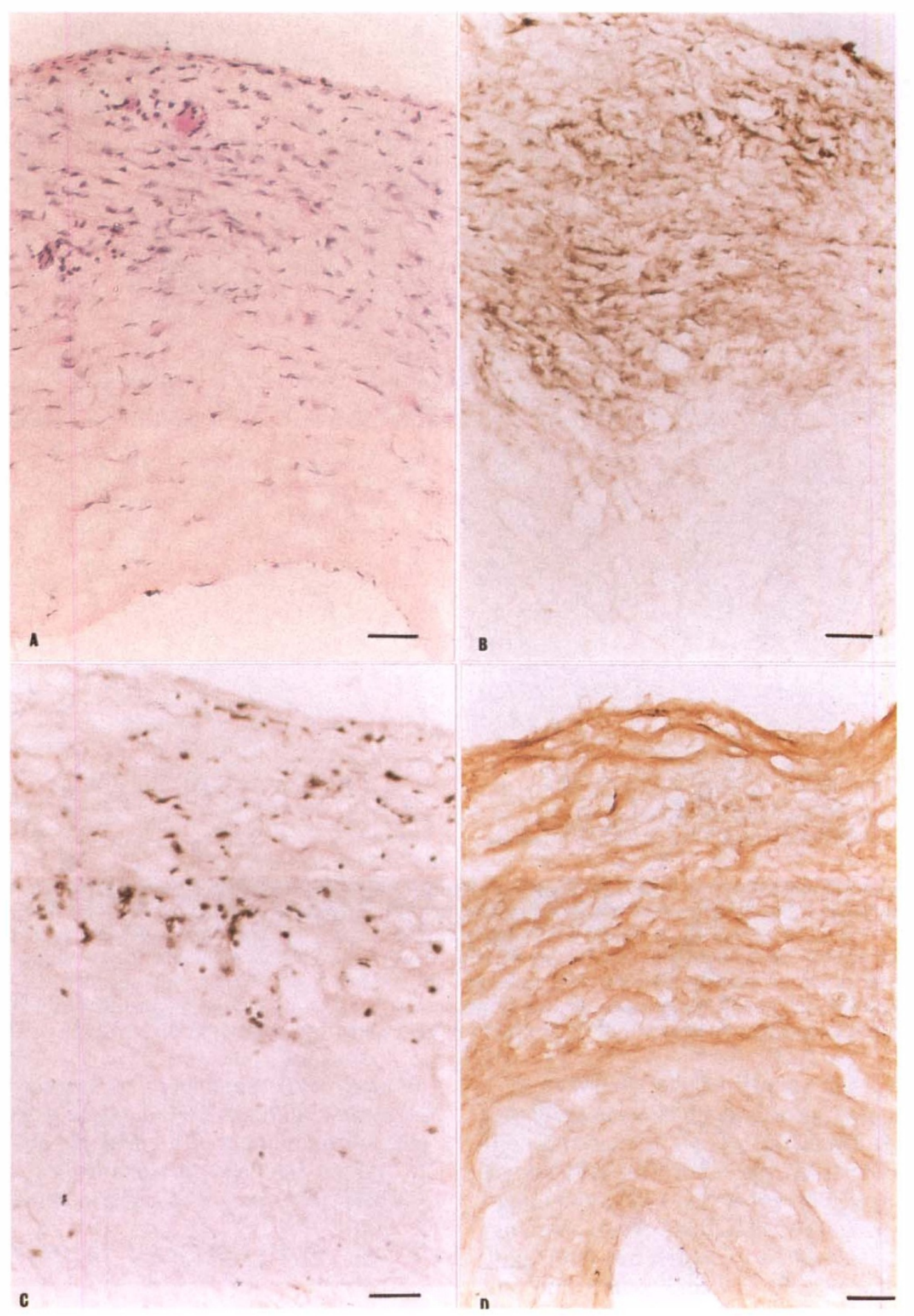

Fig. 2. Corneal button from a 74-year-old man with rheumatoid arthritis (patient 1, eighth graft) cryosectioned for histology and immunoperoxidase staining for collagenase and TIMP-1. (A) H\&E showing inflammatory mononuclear cell infiltrate and corneal fibrocyte proliferation, extending into half the corneal disc from the external surface. Epithelial cell layer was absent from the tissue section in the proximity of the cell infiltrate. (B) Monoclonal antibody RRU-CL2, showing collagenase strongly expressed in the corneal stroma in close association with the mononuclear cell infiltrate and surrounding matrix. (C) Monoclonal antibody RRU-CL1, showing cells expressing collagenase were generally of rounded morphology and close to the epithelial surface. Matrix staining was less intense than obtained with RRU-CL2. (D) Rabbit polyclonal antibody to TIMP-1, showing TIMP-1 was weakly expressed compared with normal corneas (Fig. 1D), with slightly more intense staining associated with the hypercellular regions of stroma. Scale bars represent $50 \mathrm{\mu m}$. 


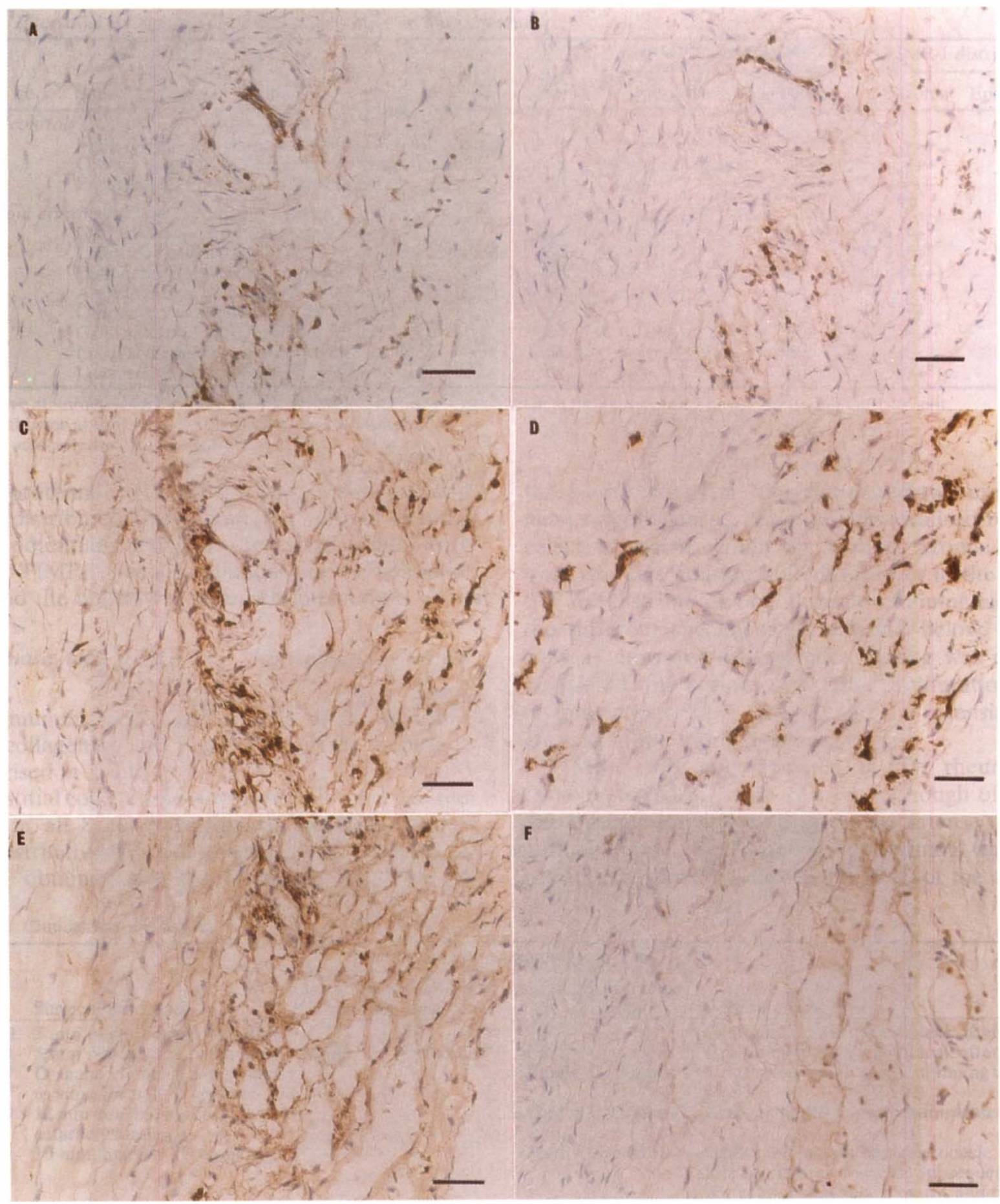

Fig. 3. Corneal button from a 74-year-old man with rheumatoid arthritis (patient 1, eighth graft) cryosectioned for immunoperoxidase staining with antibodies to cell-specific markers. (A) Helper T cells (CD4). (B) Cytotoxic T cells (CD8). (C) Monocytes/macrophages (CD68). (D) Antigen-presenting cells (HLA-DR). (E) Neuro-ectoderm (epithelial) derived cells (S100). (F) Negative control (mouse IgG). Macrophages were prominent in the cell infiltrate $(C D 68+)$, and many cells (corneal fibrocytes and macrophages) distributed throughout the stroma were activated antigen-presenting cells $(H L A-D R+)$. $A$ significant proportion of cells were derived from the epithelium or limbus (S100+), but relatively few cells were expressing T cell markers (CD4 and CD8). Scale bars represent $50 \mathrm{\mu m}$. 


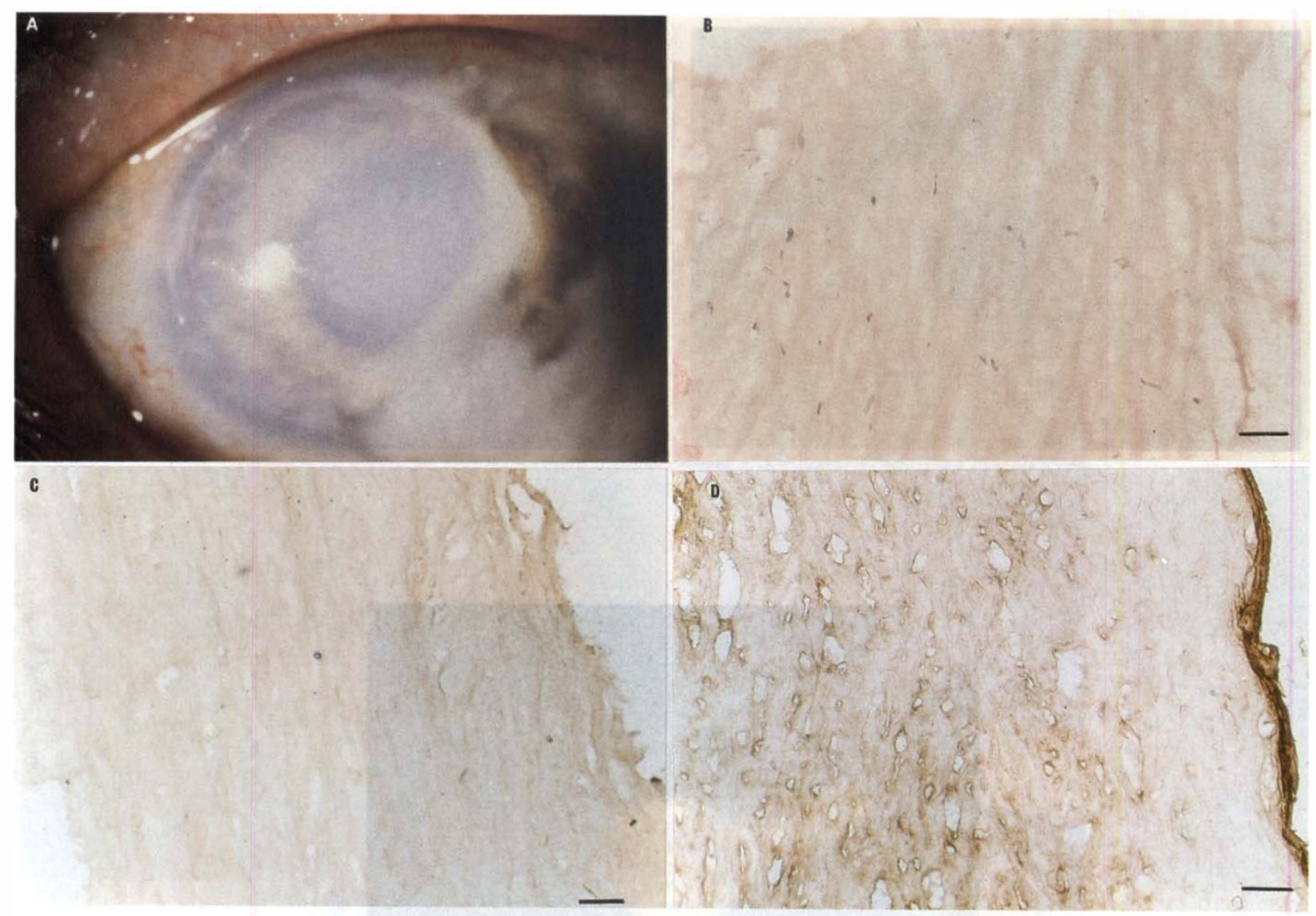

Fig. 4. (A) Appearance at presentation of a 66-year-old woman (patient 3) with long-standing rheumatoid arthritis, showing a ring of stromal infiltration around the cornea which has resulted in extensive necrosis with perforation of the cornea. The remaining cornea was grossly oedematous and infiltrated, particularly adjacent to the necrotic area. The corneal button obtained from this patient was cryosectioned for histology and immunoperoxidase staining with antibodies for collagenase and TIMP-1. (B) H\&E showing the necrotic and hypocellular stroma. The epithelium was absent from the section. (C) Monoclonal RRU-CL2, showing collagenase staining was absent from the majority of the stroma. (D) Rabbit polyclonal antibody to TIMP-1, showing TIMP-1 staining was very weak or absent from the stroma. Scale bars represent 50 pm.

and between different specimens (see below). Generally, slightly more intense staining was associated with regions infiltrated by inflammatory cells, whereas adjacent and relatively acellular regions of stroma were weakly stained or negative for TIMP.

\section{INDIVIDUAL CASE REPORTS}

\section{Patient 1}

This 70-year-old man had developed seropositive rheumatoid arthritis at the age of 23 years, when he presented with mono-arthritis of one knee and subsequent involvement of many other joints. He was treated with non-steroidal anti-inflammatory drugs, corticosteroids and gold and the joint disease became inactive at the age of 50 years. He was not severely handicapped thereafter and required only analgesic preparations. He did, however, develop extra-articular manifestations of sub-cutaneous nodules; moderate keratoconjunctivitis sicca and xerostomia. He retained some tear secretion (Schirmer's test: $5 \mathrm{~mm}$ right eye, $3 \mathrm{~mm}$ left eye).
In October 1988 he developed a spontaneous noninfectious corneal ulceration and rapid perforation of the right eye. There was no associated change in his rheumatoid arthritis. The perforation healed with a conjunctival flap and a further perforation 4 weeks later was treated with a bandage lens, and healed. In June 1989 the left eye developed a similar problem and perforated. This was treated with a conjunctival flap but the melting process continued and he had to be treated with corneal transplantation and immunosuppression. Unfortunately the disease recurred on many occasions in the grafted tissue, requiring repeated corneal transplants (Table II). Subsequently he was treated with CAMPATH- $1 \mathrm{H}$ after the tenth graft and this has since remained clear. ${ }^{24}$

Immunohistochemistry was performed on the corneal button obtained from the eighth graft to fail, following a recurrence of rheumatoid disease. Collagenase was localised to one half of the corneal disc, extending from the epithelial surface across half the thickness of the cornea and restricted to a region 

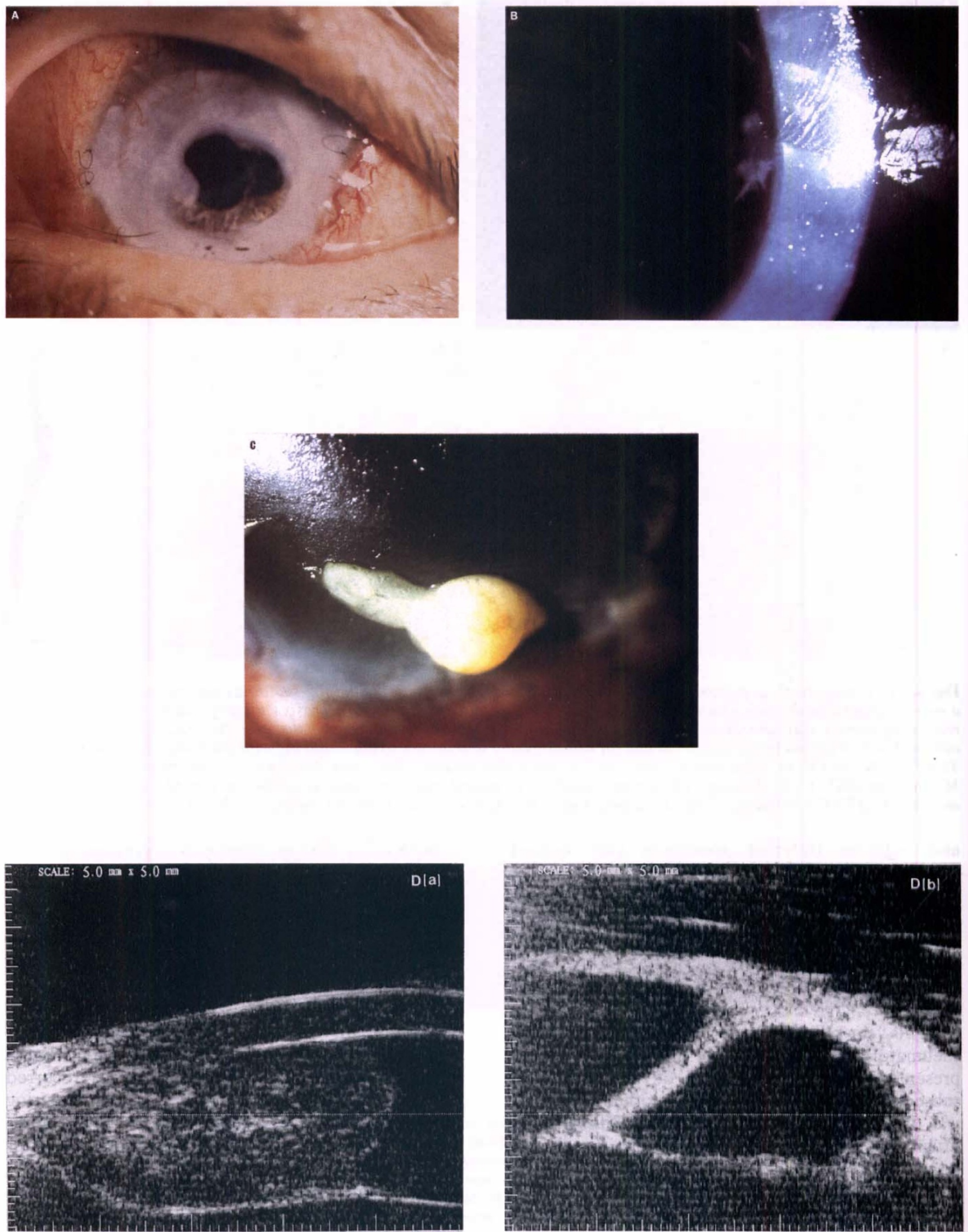

Fig. 5. Parts (A)-(D). For legend and parts (E)-(H) see opposite. 


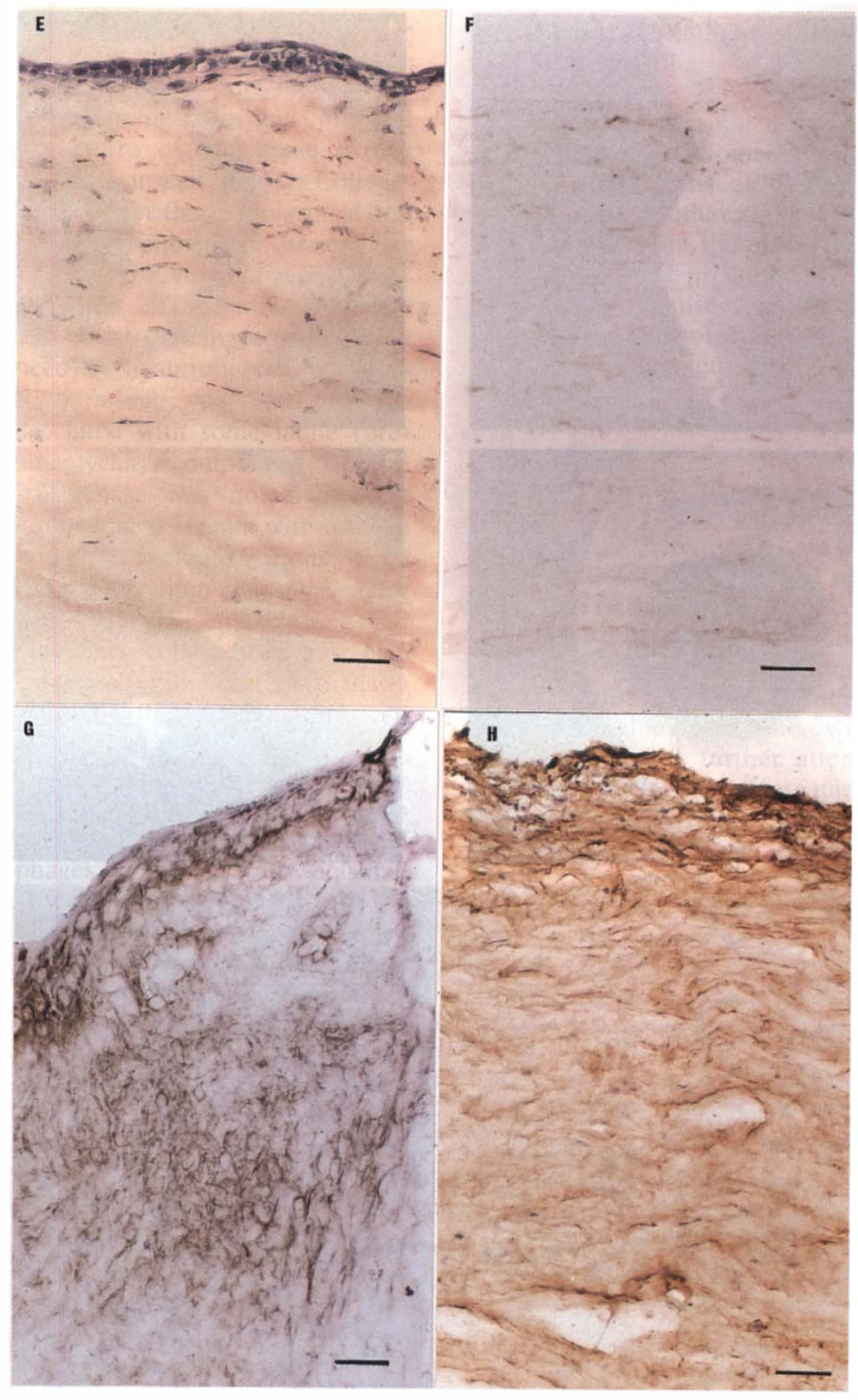

Fig. 5. (A) Appearance of the eye of a 50-year-old woman (patient 4, graft 4) on 18 March 1993 (see Table III) 13 days after grafting, showing central perforation of the cornea. (B) and (C) Appearance on 24 August 1993, nearly 3 months after the sixth graft, showing non-healing epithelium and grossly inspissated mucus, the combination of which led to the destruction of this implant. (D) Anterior segment ultrasonography prior to surgery on 17 May 1994 (sixth graft), before removal of specimen for immuno-histochemistry (specimen 2). The cornea is infiltrated but not ulcerated. There is a dense exudate in the anterior chamber with anterior and posterior synechiae (a). This has led to a collection of fluid in the posterior chamber and iris bombé (b). The corneal button removed at this time was cryosectioned for histology and immunoperoxidase staining for collagenase and TIMP-1. (E) H\&E showing the absence of inflammatory cell infiltrate in stroma and some epithelial thinning. (F) Monoclonal antibody RRU-CL2 to collagenase, showing absence of collagenase from the majority of the corneal stroma. (G) Monoclonal antibody RRU-CL2 to collagenase, showing the focus of staining and association of collagenase with cells at the corneal-scleral junction (limbus) infiltrating the edge of the cornea. (H) Rabbit polyclonal antibody to TIMP-1, showing weak to moderate staining of stroma, with more intense staining associated with cells in proximity to the epithelial surface. Scale bars represent $50 \mu \mathrm{m}$. 

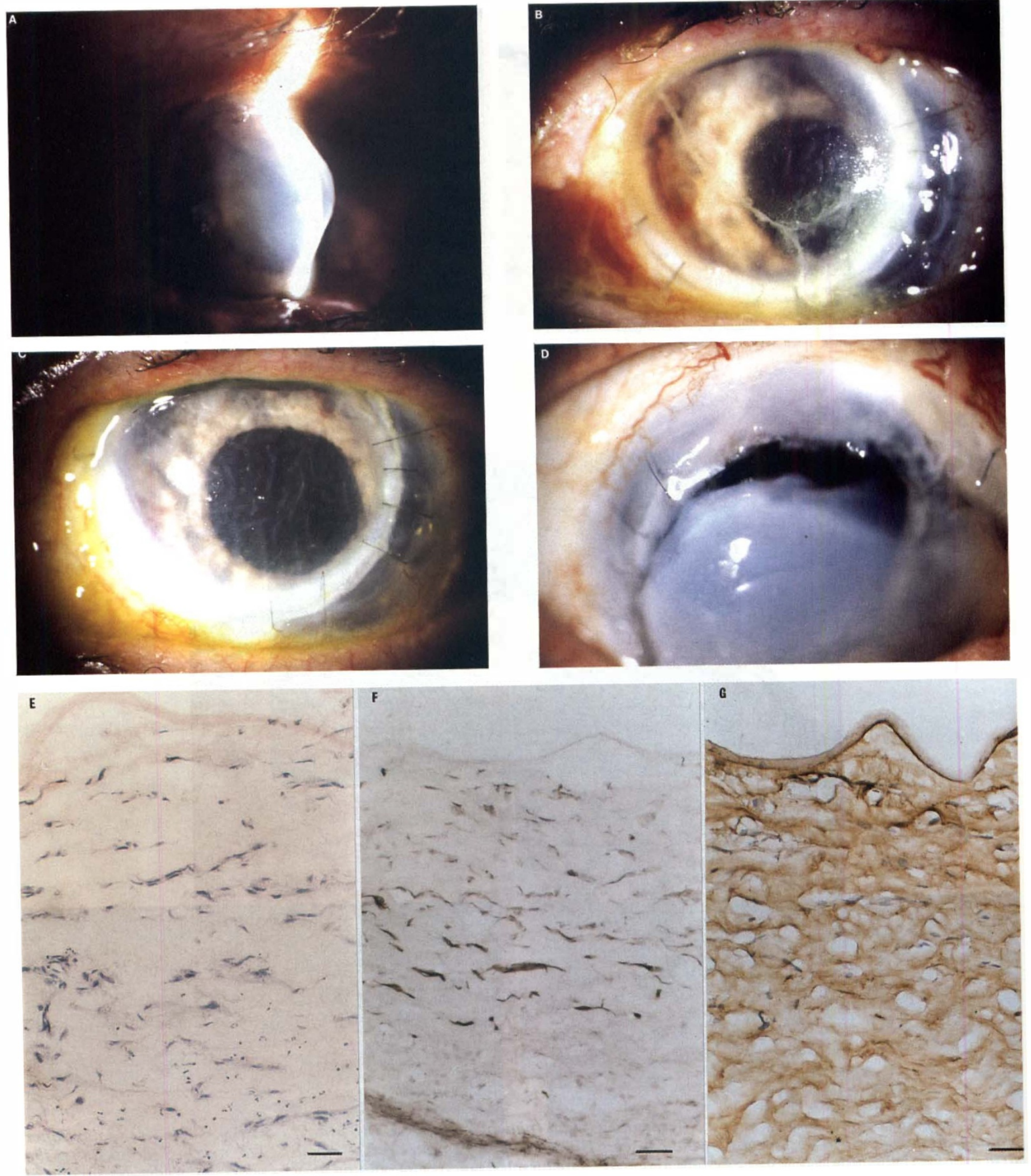

Fig. 6. (A) Pre-operative appearance of the eye of a 64-year-old man (patient 5) with grossly thickened cornea and peripheral perforation, similar to Fig. 4A. (B) Forty-eight hours post-operatively, the epithelium has shed at 2 o'clock and is very unhealthy elsewhere. (C) Three weeks later the epithelium has eventually healed, but the stroma is still oedematouk (D) Recurrent perforation 4 months later with totally opaque host and donor tissue. The corneal button obtained at this time (specimen 1) was cryosectioned for histology and immunoperoxidase staining with antibodies to collagenase and TIMP-1. (E) H\&E showing corneal fibrocyte proliferation and new blood vessel formation close to the epithelial surface with a smail number of inflammatory mononuclear cells. $(F)$ Monoclonal antibody RRU-CL2, showing association of collagenase with corneal fibrocytes aligned parallel and close to the epithelial surface. (G) Rabbit polyclonal antibody to TIMP-1, showing moderate staining of stroma. Scale bars represent $50 \mu \mathrm{m}$. 
of corneal fibrocyte proliferation and an inflammatory mononuclear cell infiltrate (Fig. 2).

There was a gradient of decreasing intensity of collagenase staining, extending from the epithelial surface towards the centre of the tissue, which correlated with the change in cell density. Collagenase was located both within the cytoplasm of the stromal cells and in the immediate pericellular matrix. The cells staining positive were generally of rounded morphology (Fig. 2C). Staining was also found associated with the surrounding stromal matrix and could be reduced by hyaluronidase pre-treatment of the section, which suggests that the collagenase was associated with some labile (presumably glycosaminoglycan) component of the stromal matrix. Collagenase was notably absent from adjacent areas of corneal stroma with a more normal cellularity and from acellular regions of the tissue. Although the epithelium and basement membrane were not always present or preserved on these frozen sections, collagenase was also detected in some regions of epithelium, particularly overlying or adjacent to the inflammatory cell infiltrate.

The composition of the cell infiltrate was characterised by a battery of monoclonal antibodies to cell surface antigens. The cell infiltrate consisted mainly of macrophages (CD68+) with a small number of helper $\mathrm{T}$ cells (CD4+) and cytotoxic $\mathrm{T}$ cells $(\mathrm{CD} 8+)$ and was characteristic of rheumatoid lesions (Fig. 3) ${ }^{3,25}$ Many cells throughout the stroma were activated antigen-presenting cells (HLA-DR+) and a small proportion of cells were expressing the
S100 antigen, a marker of cells of neuro-ectodermal (epithelial) origin.

\section{Patient 2}

This 66-year-old woman developed seropositive rheumatoid arthritis at the age of 36 years. At some time or another since then all the joints have been involved, but the only severe changes were in the hands. For the previous 2 years the pain and joint activity had diminished but still required treatment with $5 \mathrm{mg}$ prednisolone daily and indomethacin 75 mg daily. On 2 August 1994 she perforated the left cornea. The eye had not previously been uncomfortable and there was no pain. The vision was limited to counting fingers but was said to be moderately good before the eye perforated. The medication was changed to $10 \mathrm{mg}$ prednisolone daily and $75 \mathrm{mg}$ methotrexate weekly. She was immunosuppressed on this medication. The total white cell count was $9.9 \times 10^{9} / 1$ and the lymphocyte count was $0.8 \times 10^{9} / 1$. The ESR was $60 \mathrm{~mm}$ in 1 hour, but this fell when she was given $60 \mathrm{mg}$ systemic prednisolone. Initially the eye responded to tissue glue under a bandage contact lens. The glue separated without sealing the perforation and a further attempt failed. Corneal transplantation was therefore undertaken. The vision was poor (bare hand movements) before the operation but fell to no perception of light afterwards. CT scanning showed atrophy of the optic nerve and it was considered that the poor vision and other ocular changes were due to a severe rheumatoid vasculitis.

Immunohistochemistry was performed on the ulcerating host tissue obtained from this patient.

Table III. Clinical history of patient 4

\begin{tabular}{|c|c|c|c|c|}
\hline \multirow[b]{2}{*}{ Date } & \multirow[b]{2}{*}{ Surgical procedure } & \multicolumn{2}{|c|}{ Systemic immunosuppressive therapy } & \multirow[b]{2}{*}{ Clinical course } \\
\hline & & $\begin{array}{l}\text { Intra-operative pulse of i.v. } \\
\text { methylprednisolone }(500 \mathrm{mg})\end{array}$ & $\begin{array}{l}\text { Oral maintenance } \\
\text { therapy }\end{array}$ & \\
\hline 4 Apr. 92 & Patch graft over perforation & \multicolumn{2}{|c|}{ Local treatment only } & Herpetic infection. Further corneal \\
\hline 21 Sept. 92 & $12 \mathrm{~mm}$ penetrating keratoplasty & + Cyclophos $^{\mathrm{a}}$ & Pred + Cyclophos ${ }^{b}$ & $\begin{array}{l}\text { Almost immediate melting of cornea. } \\
\text { Resutured but epithelial loss and } \\
\text { perforation }\end{array}$ \\
\hline 25 Nov. 92 & $13 \mathrm{~mm}$ penetrating keratoplasty & + & Pred + CsA & Epithelial loss and continued thinning \\
\hline 5 Jan. $93^{*}$ & $13 \mathrm{~mm}$ penetrating keratoplasty & - & Pred + Cyclophos ${ }^{\mathrm{c}}$ & $\begin{array}{l}\text { Epithelium failed to heal followed by } \\
\text { central perforation } 16 \mathrm{Mar} .93\end{array}$ \\
\hline 18 Mar. 93 & $\begin{array}{l}\text { Penetrating keratoplasty. } \\
\text { Anterior vitrectomy }\end{array}$ & 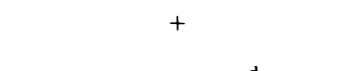 & - & $\begin{array}{l}\text { Post-op. rise of IOP controlled with } \\
\text { cyclopentolate. Epithelial loss April } 1994\end{array}$ \\
\hline 17 May $94^{*}$ & $\begin{array}{l}13 \text { mm cornea-scleral graft. } \\
\text { Total iridectomy. Organ- } \\
\text { cultured cornea }\end{array}$ & + Cyclophos $^{\mathrm{d}}$ & - & $\begin{array}{l}\text { Post-op. rise of IOP. Cyclo YAG-induced } \\
\text { graft rejection. } 30 \text { Aug. } 94 \text { Molteno implant }\end{array}$ \\
\hline 13 Sept. 94 & $\begin{array}{l}13 \mathrm{~mm} \text { cornea-scleral graft. } \\
\text { Anterior vitrectomy. Fresh } \\
\text { cornea }\end{array}$ & - & $\begin{array}{l}\text { Pred + Cyclophos }+ \\
\text { Sulphasalazine }\end{array}$ & $\begin{array}{l}\text { Graft has remained clear. Now on Cyclophos } \\
50 \text { mg once a week and } 5 \text { mg Pred. } \\
\text { Developed retinal detachment April } 1995\end{array}$ \\
\hline
\end{tabular}

Pred, prednisolone (15 mg/day); Cyclophos, cyclophosphamide; CsA, cyclosporin A (3 mg/kg/day).

*Specimen taken for immunohistochemistry.

${ }^{\mathrm{a} C}$ Cyclophos $500 \mathrm{mg}$ pre-operatively.

${ }^{\text {b Pred }} 20 \mathrm{mg}$ o.d., cyclophos $50 \mathrm{mg}$ o.d.

${ }^{\mathrm{c} C}$ Cyclophos $100 \mathrm{mg}$ o.d.

${ }^{\mathrm{d}}$ Cyclophos $250 \mathrm{mg}$ at time of operation.

${ }^{\mathrm{e}}$ Pred $10 \mathrm{mg}$ o.d., Cyclophos $50 \mathrm{mg}$ o.d., sulphasalazine $500 \mathrm{mg}$ o.d.

The same surgeon (P.G.W.) performed each graft. Topical dexamethasone $0.1 \%$ was administered after each graft. 
The intensity of staining for collagenase was much reduced compared with patient 1 and the majority of the matrix was negative. Not surprisingly, the absence of staining correlated with the relatively acellular and necrotic appearance of the corneal stroma and, unlike patient 1 , there was no substantial influx of mononuclear inflammatory cells (Fig. 4).

The small amount of collagenase that was present in the stroma was associated with a small number of cells close to the epithelial surface of the tissue (not shown). TIMP-1 was only very weakly expressed or absent from the whole corneal stroma, although there was more intense staining at the basement membrane/epithelial surface which was thought not to be an edge effect or artefact of staining (Fig. 4D).

\section{Patient 3}

This 76-year-old man recently developed seropositive rheumatoid arthritis involving hands, elbows and knee joints. This responded to treatment with gold and non-steroidal anti-inflammatory drugs. However, after 2 years he developed a red painful eye. Examination showed an extensive painful corneal gutter, which rapidly progressed to perforation requiring penetrating keratoplasty. The specimen was obtained from host tissue at the first grafting operation.

The intensity and distribution of collagenase staining in the corneal button were essentially similar to that observed for patient 1 , with a strong association of collagenase with an extensive inflammatory cell infiltrate, extending from the epithelial surface. Collagenase was also associated with the epithelium where present on the section, although the full thickness of epithelial cells was lost from the region in close proximity to the inflammatory cell infiltrate.

\section{Patient 4}

This 50-year-old woman developed seropositive rheumatoid arthritis as an acute illness at the age of 33 years. There was rapid progression of her disability, in spite of intensive treatment. She required surgical treatment for her joint disease (23 operations in all) and by this means maintained her mobility and remained relatively pain free. A paternal aunt and a brother also suffer from rheumatoid arthritis. By 1991 the arthritis had become relatively inactive but she then developed an infected knee joint and a severe gram-negative septicaemia with renal failure, congestive heart failure and temporary antro-vascular accident. The recovery was prolonged but complete. In 1992 she developed a non-infectious corneal ulcer in the left eye. This was treated by a penetrating keratoplasty. Three months later she developed a herpetic keratitis which resulted in perforation of the cornea. Since then she has had multiple corneal transplants due to recurrence of the original disease in the graft. The final $13 \mathrm{~mm}$ keratoplasty has remained clear to date (Table III).

Two specimens from the fourth and sixth grafts respectively were taken for immunohistochemical analysis. In the first specimen (fourth graft), collagenase was moderately abundant in the stroma and associated with a mononuclear cell infiltrate much as described in patients 1 and 3 (not shown). In the second specimen (sixth graft), collagenase was absent from much of the corneal stroma, the majority of which had a relatively normal histology, although there were some regions of fibrocyte proliferation and epithelial thinning (Fig. 5).

The relative absence of collagenase was consistent with the immunosuppressed (quiescent) nature of the host disease which was noted at the time of keratoplasty. However, a small focus of collagenase staining was found, but restricted to one edge of the corneal disc, to the pericellular domain of cells infiltrating from the corneal-scleral junction or limbus (Fig. 5G). In both specimens, TIMP-1 staining was of weak to moderate intensity, and marginally increased in the more cellular regions of the stroma.

\section{Patient 5}

This 64-year-old man had had severe rheumatoid arthritis since the age of 24 years. All his joints became affected and he had both hips and knees replaced. The joint disease became quiescent in the late 1980s but he had increasing chest pain on exercise and showed evidence of diffuse arterial disease. He had a strong family history of rheumatoid arthritis, his mother and sister being severely affected.

In July 1992 he developed an irritation in his left eye and was found to have a corneal gutter which progressed in spite of treatment, and perforated. This was treated initially by conjunctival excision but this did not improve the condition. He was found to have an active rheumatoid vasculitis so he was treated with methylprednisolone and cyclophosphamide and the gutter healed. One month later, however, he developed a staphylococcal endophthalmitis; this responded to antibiotics but the cornea became extremely thin. Grafting was delayed because he had developed chest pain at rest. However, by November 1992 he was able to have an eccentric patch graft, cataract extraction and intra-ocular lens implantation. Histology of the cornea, iris and ciliary body removed at the time showed extensive infarction of this tissue.

This and subsequent grafts survived for short periods ( 6 months and 2 months respectively) and then he had a recurrence of the corneal ulceration. 
The graft was repeated and the final graft remained cloudy but viable until his death 1 year later. Latterly he developed a retinal detachment but this was not treated.

In the first graft specimen to be obtained from this patient, there was relatively little mononuclear cell infiltrate, although there was an increase in corneal fibrocytes, with some small bundles of cells having the appearance of new blood vessels. Collagenase was mainly associated with corneal fibrocytes, many of which were aligned parallel and close to the epithelial surface (Fig. 6).

In the subsequent two corneal specimens, collagenase was also relatively abundant in the stromal matrix, but associated particularly with clumps of rounded cells in regions of an extensive inflammatory cell infiltrate, similar to that described previously (not shown). In all specimens, TIMP-1 staining was of weak to moderate intensity, with a slightly greater intensity in association with the cellular infiltrate or fibrocytes, particularly close to the epithelial surface as shown in Fig. $6 \mathrm{G}$.

\section{Characterisation of the Inflammatory Cell Infiltrate}

Although there were some differences in the quantity of cells between the different specimens, the composition of the mononuclear cell infiltrate (where present) was generally similar in each of the rheumatoid corneas and characteristic of rheumatoid lesions (Fig. 3). ${ }^{3,25-27}$ There were relatively few $\mathrm{T}$ cells and the most abundant cells were macrophages. Many cells both within the infiltrate and throughout the corneal stroma were expressing the HLA-DR antigen, indicating activated antigen-presenting cells. None of the cell markers was present in histologically normal corneas, with the exception of a few activated macrophages (HLA-DR +ve, CD68 +ve) in the region of scarring and collagenase expression found in one of the normal specimens (not shown).

\section{DISCUSSION}

Sterile corneal ulceration is a rare but potentially devastating complication of rheumatoid arthritis. ${ }^{1}$ The pathogenesis is unknown, but is presumed to be an immune-mediated process, associated with an inflammatory response at the corneal-scleral junction with mononuclear cells infiltrating the cornea from the limbus. ${ }^{28}$ However, as yet there is no unifying hypothesis to explain the occurrence of central and paracentral corneal ulcers, which often present without ocular inflammation, although previous epithelial injury and aqueous tear deficiency have been implicatę. ${ }^{3}$

This is the first report of the possible role of the matrix metalloproteinase collagenase (MMP-1) and its inhibitor (TIMP-1) in the pathogenesis of corneal destruction in rheumatoid arthritis. Interstitial col- lagenase was abundantly expressed by cells in the corneal stroma in 6 of 8 ulcerating rheumatoid corneas, but was not found in histologically normal corneal stroma. In the remaining 2 rheumatoid specimens, collagenase was weakly expressed in small foci of infiltrating cells, but absent from most of the stroma, probably as a result of tissue necrosis in one case (patient 2) and quiescent disease in the other (patient 4, specimen 2). Although we did observe some collagenase in 'normal' corneal epithelium, this is probably a result of previous traumatic insult in one case, and the culturing of the cornea in the other cases - a procedure which is known to induce collagenase expression in the cornea. $^{12}$

Interstitial collagenase (MMP-1) can be produced by a variety of tissue cells including fibroblasts and macrophages and is one of the few enzymes capable of cleaving fibrillar collagens within the collagen triple-helix. $^{13,14}$ Thus the control of collagenase activity is thought to be the rate-limiting process in the turnover and remodelling of connective tissues, in both normal and pathological situations. Although previous studies have reported metalloproteinase and specifically collagenase activity produced by corneal fibrocytes in ulcerating and remodelling corneas, ${ }^{10-12,28,29}$ to our knowledge this is the first study to examine the distribution of both MMP-1 and its specific inhibitor (TIMP-1) in patients with wellcharacterised rheumatoid disease. Our observations are consistent with the hypothesis that MMP-1 is one of the major enzymes involved in the degradation of the corneal matrix seen in rheumatoid corneal ulceration.

Collagenase and other metalloproteinases are synthesised and secreted as inactive pro-enzymes, which are activated in the matrix by proteolytic cleavage. ${ }^{13,14,16}$ Once activated, levels of collagenase activity are dependent on the local concentration of the TIMPs, which rapidly form a tightly bound inactive complex with active metalloproteinases. ${ }^{17,19}$ In this study we have shown that TIMP-1 is abundantly expressed throughout the normal corneal stroma, presumably bound to some component of the stromal matrix. The presence of TIMP in the normal stroma is likely to have a physiological role maintaining corneal integrity, as it has been shown that both synthetic metalloproteinase inhibitors and recombinant TIMP-1 can prevent corneal ulceration in animal models. ${ }^{30,31}$ TIMP-1 and TIMP-2 have previously been shown to be produced by normal corneal fibrocytes, ${ }^{32,33}$ and together with non-specific protease inhibitors produced in the cornea such as $\alpha_{2}$-macroglobulin, ${ }^{18}$ would provide a reservoir of inhibitory activity against metalloproteinase activity and act to maintain tissue homeostatis.

In this study we found that TIMP-1 was also 
expressed in the majority (7/8) of rheumatoid corneas, but the intensity of staining was much weaker than in normal corneas, in particular in the hypocellular and acellular regions of the stroma. Of course the methods used in this study do not provide quantitative data on the relative levels of collagenase and TIMP, but our observations are consistent with the hypothesis that collagen degradation is occurring where levels of active collagenase are in excess of levels of TIMP. We also observed that TIMP was relatively more abundant in the hypercellular regions of stroma - areas which also contained cells expressing collagenase. We could not determine in this study whether collagenase and TIMP were being expressed by the same or different cells within the infiltrated tissue, although coordinate expression of enzyme and inhibitor has been reported in fibroblast cell cultures. ${ }^{34}$ This presumably represents a homeostatic mechanism to control excessive local tissue destruction. Our observations would suggest that in normal cornea, levels of TIMP and other proteinase inhibitors are sufficient to inhibit any metalloproteinase activity. In destructive corneal disease, reduced local levels of TIMP-1 production may be permissive of excessive matrix degradation by collagenase and other metalloproteinases. However, more work needs to be done to investigate the production of other matrix metalloproteinases in diseased cornea, in addition to metalloproteinase inhibitors such as TIMP-2, TIMP-3 and $\alpha_{2}$-macroglobulin.

The cellular source of the collagenase and TIMP-1, and the precise nature of the antigenic stimulus and/ or inflammatory mediators driving the process of corneal destruction, remain the source of some conjecture. Matrix metalloproteinases can be produced by a variety of different cell types in the eye. Stromal fibroblasts can express interstitial collagenase (MMP-1) and stromelysin (MMP-3), ${ }^{29}$ and both epithelial and stromal cells produce collagenase in addition to the $72 \mathrm{kDa}$ and $92 \mathrm{kDa}$ gelatinases (MMP-2 and MMP-9 respectively). ${ }^{35}$ In this study we found that collagenase (MMP-1) was strongly associated with an inflammatory mononuclear cell infiltrate, similar to that described previously in ulcerating rheumatoid corneas, ${ }^{3,25}$ in scleritis ${ }^{26}$ and in rheumatoid joint synovium. ${ }^{36}$ The high density of activated macrophages suggests that these cells might be the source of the enzyme. However, the corneal fibroblasts might also be synthesising collagenase in response to pro-inflammatory cytokines (such as interleukin-1), which are produced by activated macrophages and have been shown to up-regulate collagenase expression in corneal stromal cells. ${ }^{37}$

Fibrocytes and macrophages throughout the corneal stroma were expressing HLA-DR antigens, demonstrating activation in response to either direct antigenic stimulation and/or the production of local inflammatory mediators. Although $\mathrm{T}$ cells might be the source of activating cytokines such as interferon $\gamma$, the low number of $T$ cells present in the ulcerating corneas might suggest a lesser role for these cells and their products. Many infiltrating cells were also expressing the S100 antigen, a marker of cells of neuro-ectodermal origin, such as dendritic Langerhans cells derived from the epithelium and/or limbus. These phagocytic cells are presumably migrating into the tissue in response to mitogenic stimuli produced by cells in the stroma. Candidate signalling molecules include pro-inflammatory cytokines such as interleukin- 1 and tumour necrosis factor alpha, both of which have been associated with ocular inflammation as reviewed by Kijlstra. ${ }^{27}$ Briefly, corneal cells from the stroma and epithelium both produce and respond to interleukin-1, which can stimulate the production of prostaglandins and cytokines such as interleukin-6, monocyte chemotactic protein (MCP) and interleukin-8, which in turn attract and activate macrophages and leucocytes thus amplifying the inflammatory response. This might occur as a result of damage to the epithelium and/or some component of the stromal matrix, perhaps revealing hidden epitopes which can stimulate the development of an autoimmune response in susceptible individuals, although the relative contribution of humoral and cellmediated immunity to this process is unknown. However, the macrophage and other antigen-presenting cells are likely to play a major role in both initiating and maintaining the chronic inflammatory response and corneal destruction, as described in other rheumatoid lesions. ${ }^{38}$

Finally a number of studies have demonstrated the importance of interactions between epithelial and stromal cells, which are a requirement for the induction of collagenase in corneal fibrocytes in culture. ${ }^{10,32}$ In this study we observed that the intensity of collagenase staining was generally more intense closer to the epithelial surface, consistent with the progression of ulceration from the epithelium to the stroma. One explanation for this distribution might be the production of some signalling molecule(s) derived from the epithelium such as platelet activating factor (PAF), a lipidderived inflammatory mediator which is generated in the cornea in response to injury and inflammation and stimulates collagenase expression by corneal epithelial cells. ${ }^{39}$ Other studies have reported immune complexes deposited in the epithelial cell layer in ulcerating rheumatoid corneas, 3,25 although the pathological significance of these observations is unknown. We and others have previously noted the importance of maintaining the integrity of the epithelial layer in the success of corneal grafts., ${ }^{3,9,25}$ Taken together, these observations would suggest a link between cell-mediated events occurring at or 
close to the epithelial surface of the cornea, involving macrophage infiltration from the limbus, collagenase expression and activation by corneal fibrocytes within the stroma, a reduction in TIMP expression and ultimately corneal destruction.

This work was supported by grants from the Arthritis and Rheumatism Council for Research (Great Britain) and by the Cambridge Arthritis Research Endeavour (CARE).

Key words: Collagenase, Cornea, Corneal ulceration, Rheumatoid arthritis, TIMP.

\section{REFERENCES}

1. Hazleman BL, Watson PG. Ocular complications of rheumatoid arthritis. Clin Rheum Dis 1977;3:501-26.

2. Brown SI, Grayson M. Marginal furrows: a characteristic lesion of rheumatoid arthritis. Arch Ophthalmol 1968;79:563-7.

3. Kervick GN, Pflugfelder SC, Haimovici R, Brown H, Tozman E, Yee R. Paracentral rheumatoid corneal ulceration: clinical features and cyclosporin therapy. Ophthalmology 1992;99:80-8.

4. Jayson MIV, Easty DL. Ulceration of the cornea in rheumatoid arthritis. Ann Rheum Dis 1977;36:428-32.

5. Watson PG, Hazleman BL. The sclera and systemic disorders. London: Saunders, 1976.

6. Meyer PA, Watson PG, Franks W, Dubord P. Pulsed immunosuppressive therapy in the treatment of immunologically induced corneal and scleral disease. Eye 1987;1:487-95.

7. Hill JC. Systemic cyclosporine in high risk keratoplasty: short- versus long-term therapy. Ophthalmology 1994;101:128-33.

8. Mackay IR, Bignell JL, Smith PH, Crawford BA. Prevention of corneal graft failure with the immunosuppressive drug azathioprine. Lancet 1967;ii:479-82.

9. Bernauer W, Ficker LA, Watson PG, Dart JKG. The management of corneal perforations associated with rheumatoid arthritis. Ophthalmology 1995; accepted for publication.

10. Itoi M, Gnadinger MC, Slansky HH, Freeman MI, Dohlman CH. Collagenase in the cornea. Exp Eye Res 1969;8:369-73.

11. Brown SI, Weller CA, Wasserman HE. Collagenolytic activity of alkali burned corneas. Arch Ophthalmol 1969;81:370-6.

12. Gordon JM, Bauer EA, Eisen AZ. Collagenase in human cornea. Arch Ophthalmol 1980;98:341-5.

13. Woessner JF. Metalloproteinase and their inhibitors in connective tissue remodelling. FASEB J 1991;5: 2145-54.

14. Matrisian LM. The matrix degrading metalloproteinases. BioEssays 1992;14:455-63.

15. Freije JMP, Diez-Itza ID, Balbin M, Sanchez LM, Blasco R, Tolivia J, Lopez-Otin C. Molecular cloning and expression of collagenase-3, a novel human matrix metalloproteinase produced by breast carcinomas. J Biol Chem 1994;269:16766-73.

16. Bermann MB. Regulation of corneal fibroblast MMP-1 collagenase secretion by plasmin. Cornea 1993;12: 420-32.

17. Cawston TE, Galloway WA, Mercer E, Murphy G, Reynolds JJ. Purification of rabbit bone inhibitor of collagenase. Biochem J 1981;195:159-65.

18. Twining SS, Fukuchi T, Yue BYJT, Wilson PM, Zhou $\mathrm{X}$, Loushin G. $\alpha_{2}$-Macroglobulin is present in and synthesised by the cornea. Invest Ophthalmol Vis Sci 1994;35:3226-33.

19. Cawston TE. Metalloproteinase inhibitors. In: Barrett AJ, Salverson G, editors. Proteinase inhibitors. New York: Elsevier, 1986:589-610.

20. Clark IM, Powell LK, Wright JK, Cawston TE, Hazleman BL. Monoclonal antibodies against human fibroblast collagenase and the design of an enzyme linked immunosorbent assay to measure total collagenase. Matrix 1992;12:475-80.

21. Clark IM, Wright JK, Cawston TE, Hazleman BL. Polyclonal antibodies against human fibroblast collagenase and the design of an enzyme linked immunosorbent assay to measure TIMP-collagenase complex. Matrix 1992;12:108-15.

22. Clark IM, Powell LK, Wright JK, Cawston TE, Hazleman BL. Polyclonal and monoclonal antibodies against human tissue inhibitor of metalloproteinases (TIMP) and the design of an enzyme linked immunosorbent assay to measure TIMP. Matrix 1991;11:76-85.

23. Hewitt RE, Leach IH, Powe DG, Clark IM, Cawston TE, Turner DR. Distribution of collagenase and tissue inhibitor of metalloproteinases (TIMP) in colorectal tumours. Int J Cancer 1991;49:666-72.

24. Newman DK, Isaacs JD, Watson PG, Meyer PAR, Hale $G$, Waldmann $H$. Prevention of immunemediated corneal graft destruction with the antilymphocyte monoclonal antibody, CAMPATH-1H. Eye 1995;9:564-9.

25. Michels ML, Cobo LM, Caldwell DS, Rice JR, Haynes BF. Rheumatoid arthritis and sterile corneal ulceration. Arth Rheum 1984;27:606-14.

26. Bernauer W, Watson PG, Daicker B, Lightman S. Cells perpetuating the inflammatory response in scleritis. Br J Ophthalmol 1994;78:381-5.

27. Kijlstra A. The role of cytokines in ocular inflammation. Br J Ophthalmol 1994;78:885-7.

28. Eiferman RA, Carothers DJ, Yankeelov JA. Peripheral rheumatoid ulceration and evidence for conjunctival collagenase production. Am J Ophthalmol 1979;87: 703-9.

29. Girard MT, Matsubara M, Kublin C, Tessier MJ, Cintron C, Fini ME. Stromal fibroblasts synthesise collagenase and stromelysin during long-term connective tissue remodelling. J Cell Sci 1993;104:1001-11.

30. Paterson CA, Wells JG, Koklitis PA, Higgs GA, Docherty AJP. Recombinant tissue inhibitor of metalloproteinases type I suppresses alkali burninduced corneal ulceration in rabbits. Invest Ophthalmol Vis Sci 1994;35:677-84.

31. Fini ME, Cui T, Mouldovan A, Grobelny D, Galardy RE, Fisher SJ. An inhibitor of the matrix metalloproteinase synthesised by rabbit corneal epithelium. Invest Ophthalmol Vis Sci 1991;32:2997-3001.

32 Brown D, Chwa M, Escobar M, Kenney MC. Characterisation of the major matrix degrading metalloproteinase of human corneal stroma: evidence for an enzyme/inhibitor complex. Exp Eye Res 1991;52:5-16.

33. Opbroek A, Kenney MC, Brown D. Characterisation of a human corneal metalloproteinase inhibitor. Curr Eye Res 1993;12:877-83.

34. Murphy G, Reynolds JJ, Werb Z. Biosynthesis of tissue inhibitor of metalloproteinases by human fibroblasts in culture: stimulation by $12-O$-tetradecanoylphorbol $13-$ acetate and interleukin-1 in parallel with collagenase. $J$ Biol Chem 1985;260:3079-83.

35. Fini ME, Girard MT. Expression of collagenolytic/ gelatinolytic metalloproteinases by normal cornea. Invest Ophthalmol Vis Sci 1990;31:1779-88. 
36. Palmer DG. The anatomy of the rheumatoid lesion. $\mathrm{Br}$ Med Bull 1995;51:286-95.

37. Girard MT, Matsubara M, Fini ME. Transforming growth factor B and interleukin-1 modulate metalloproteinase expression by corneal stromal cells. Invest Ophthalmol Vis Sci 1991;32:2442-54.
38. Viner NJ. Role of antigen presenting cells in rheumatoid arthritis. Br Med Bull 1995;51:359-67.

39. Bazan HEP, Tao Y, Bazan NG. Platelet activating factor induces collagenase expression in corneal epithelial cells. Proc Natl Acad Sci USA 1993; 90:8678-82. 